\title{
El infierno terrenal en los orígenes del Heavy Metal.
}

The Earthly Hell on the origins of Heavy Metal.

DOI: $10.32870 /$ sincronia.axxv.n79.26a21

\author{
Bianca Natascha Pérez González * \\ Universidad de Guadajalara (MÉXICO) \\ CE: nataschaperez18@gmail.com / ID ORCID: 0000-0002-2281-5409
}

\begin{abstract}
* Licenciada en Letras Hispánicas y pasante de la Maestría en Literaturas comparadas por la Universidad de Guadalajara. Actualmente cursa la Licenciatura en Antropología, por la Universidad de Guadalajara y se desempeña como docente de Lengua Española y Humanidades a nivel bachillerato.
\end{abstract}

Esta obra está bajo una Licencia Creative Commons Atribución-NoComercial 4.0 Internacional

Recibido: $27 / 01 / 2020$

Revisado: $18 / 10 / 2020$

Aprobado: $17 / 11 / 2020$

\section{RESUMEN}

El Heavy Metal, como movimiento artístico y de compromiso social nace como una expresión de contracultura en su negación por formar parte de una sociedad plagada de incongruencias éticas y morales, estableciendo el Existencialismo como su fundamento filosófico dominante.

En el contexto religioso decadente que caracterizó al siglo XX, Jean - Paul Sartre engendra dos obras teatrales, A puerta cerrada y El diablo y dios, que vendrán a establecer las bases de uno de los infiernos más trascendentes para el pensamiento contemporáneo: la otredad.

En su música, Black Sabbath, como grupo pionero de este género musical, contiene en sus letras el concepto sartreano de La Otredad como infierno terrenal. A partir de la deconstrucción simbólica del mito del cielo y el infierno de la tradición cristiana occidental, Black Sabbath resemantiza el infierno para proponer una explicación racional a las problemáticas de su época y convertirlo en la metáfora del desencanto y el nihilismo de una 
Europa moderna, en la que los íconos míticos están siendo reemplazados por representaciones de la realidad concreta.

Palabras Clave: Jean-Paul Sartre. Black Sabbath. Otredad. Infierno. Mitos.

\begin{abstract}
Heavy Metal, as a movement of art and social commitment was born as an expression of counterculture in its denial to be part of a society plagued by ethical and moral incongruities, establishing Existentialism as its dominant philosophical foundation.

In the decadent religious context that characterized the twentieth century, the french philosopher Jean- Paul Sartre begets two plays, No Exit (1944) and The Devil and the Good Lord (1951), that will come to lay the foundations of one of the most transcendent hells for contemporary thought: otherness.

In his music, Black Sabbath, as a pioneering group of this musical genre, contains in his lyrics the Sartrean concept of The Otherness as earthly hell. From the symbolic deconstruction of the myth of heaven and hell from the Western Christian tradition, Black Sabbath re-signifies hell to propose a rational explanation of the problems of his time and to make it the metaphor for the disillusionment and nihilism of a modern Europe, in which mythical icons are being replaced by representations of concrete reality.
\end{abstract}

Keywords: Jean-Paul Sartre. Black Sabbath. Otherness. Hell. Myths.

\title{
Introducción
}

La aparición de El otro como motivo literario ha sido una constante, ya sea como expresión de la angustia del ser humano ante la amenaza de aquello que le es ajeno - y por tanto no puede tener control sobre ello-, como medio para expresar el miedo a seres y entes demoníacos que aparentemente- rondan el mundo de los vivos o bien o como revelación del temor hacia los monstruos, fantasmas y demonios internos, que lo atormentan. 
Debido a la tradición occidental de definir la realidad a partir de un pensamiento binario, no podemos dejar de hablar del nosotros cuando hablamos del yo. Para que el yo se defina, necesita contrastarse con el otro, con su alter ego: "La alteridad... siempre complica la existencia del yo, por eso la forma más adecuada de hablar de ella es el nosotros." (Ruiz. 2007, p. 9). Esta dualidad es el resultado de "una sociedad que siempre mira a sí misma - narcisista- [y que] genera el fantasma, el desdoblamiento e incluso la invisibilidad: la anulación total del individuo en la sociedad" (Ballesteros, 1998).

El Heavy Metal como movimiento artístico y social nace como una expresión de contracultura en su negación por formar parte de esa otredad de falsa moral, estableciendo el existencialismo como una de sus bases ideológicas predominantes. Black Sabbath, como grupo pionero de este género musical, propone una deconstrucción del mito del cielo y el infierno de la tradición cristiana occidental para contener en sus canciones el infierno terrenal sartreano.

Wicked world, Luke's Wall, Hand of doom, Solitude e Into the void (Black Sabbat, 1971a) son algunas de las canciones de la banda inglesa en las cuales el Infierno asciende a la Tierra en el momento en que la otredad se reconoce como motivo de sufrimiento. Dicho en palabras del autor: "El infierno son los otros".

El siglo XX es el siglo de los infiernos, según George Minois (2005, p.453). Ya desde el siglo XIX, en el apogeo del Romanticismo y bajo la influencia estética e ideológica de Los Poetas Malditos, los fundamentos sobre los cuales se había construido el infierno cristiano durante casi dos milenios comienzan a flaquear. Los devotos todavía acudían a las ceremonias litúrgicas y cumplían con sus deberes religiosos, sin embargo, comienzan a negar la existencia de un inframundo real, físico, con llamas y lamentos. Esto deriva en un replanteamiento total de la cosmovisión europea occidental, por un lado, mientras que, por otra parte, el infierno comienza a multiplicarse hasta convertirse en un infierno a la medida de cada individuo. El infierno se transforma en los infiernos (Minois, 2005, p.425).

Así pues, en tanto que los clérigos sostienen firmemente la realidad del infierno tangible, geográficamente ubicado en el corazón de la tierra, para ratificar el temor de dios a través del 
miedo al sufrimiento físico eterno, los escritores, filósofos, artistas y pensadores paganizan el averno y proponen nuevos escenarios donde sufrir la condena del Juicio Final, espacios ya no sólo físicos, sino también espirituales.

En el contexto religioso decadente que caracterizó al siglo XX, Jean - Paul Sartre engendra dos obras teatrales, A puerta cerrada y El diablo y dios, que vendrán a establecer las bases de uno de los infiernos más trascendentes para el pensamiento contemporáneo: la otredad.

Si algo es claro es que, desde su origen, el hombre se ha visto amenazado por la angustia de saber quién es y si realmente es como los otros lo ven. El otro se transforma entonces en su antítesis y enemigo, pero en su espejo a la vez: el hecho de que el otro sepa más del yo que el yo mismo, confiere a la alteridad cierto poder sobre ese yo, quien inconsciente o conscientemente se convierte en su prisionero y esclavo. Así lo plantea Black Sabbath en Luke's Wall, al explicar que los otros hacen la guerra sólo por diversión y tratan a la gente como peones de ajedrez ${ }^{1}$.

Sartre menciona que ser malo implica necesitar el sufrimiento de otros para existir (1944, p.21). Por ende, la otredad de la que habla Black Sabbath en el fragmento anterior es igualmente malvada, ya que se regocija en el sufrimiento de los demás frente a la guerra provocada por ese ente poderoso indeterminado, al igual que disfruta jugar con ellos y su destino como piezas de ajedrez, metáfora donde además se cosifica al hombre.

Black Sabbath deja bien en claro que "Dios ha muerto". Ya no es ese ser sobrenatural quien posee el poder de dar muerte y juzgar a la humanidad, ahora ese rol lo cumple la misma humanidad, aunque no a todos les confiere la facultad de ejecutarlo, sino únicamente a aquellos a quienes su mismo linaje ha elegido como líderes: el político, por ejemplo, juzga y da muerte al hombre subordinado, inferior; él tiene que elegir quien vive y quien muere en Wicked world. (Black Sabbath, 1969). ${ }^{2}$

Dios ya no es todopoderoso, ahora se trata más bien de un superhombre nietzscheano, dotado de un poder que el mismo hombre -semejante, pero alteridad a la vez- le otorgó,

\footnotetext{
1 "Making war just for fun / treating people just like pawns in chess / wait 'till their judgement day comes..."

2 "A politician's job they say is very high / for he has to choose who's got to go and die".
} 
transformándolo así en verdugo y dueño del destino de la tierra y sus habitantes, de la voluntad y la libertad humana tal como manifiesta la banda de Birgminhan en un fragmento de Lord of this world: "Tú me hiciste el creador del mundo donde existes / el alma que tomé de ti ni siquiera hizo falta" (Black Sabbat, 1971b).

Además del poder, el abuso y las guerras, la simulación transforma a la alteridad en el infierno de sus semejantes. En una realidad maliciosa y perversa "el mundo es una cosa tan malvada" (Black Sabbath, 1969). Mientras algunos envían buenos deseos a sus amigos, otros cuentan las muertes ocasionadas por las manos del hombre, explica Wicked world. Dios y su contraparte, el Diablo, conviven ahora en la tierra: "People give good wishes to all their Friends / while people just acorss the sea is counting the dead" (Black Sabbath, 1969).

Una serie de dicotomías culturales resultan de estos versos. Los buenos deseos, los amigos y la bondad corresponden a un espacio cercano al emisor: la bondad está aquí; mientras que la muerte, la fatalidad y la maldad se encuentran en un espacio lejano, dividido por un mar: la maldad, pues, está allá. Cualquiera que sea ese mar al que refiere, éste se transforma en la metáfora de la frontera entre lo ajeno y lo propio, lo extraño y lo conocido, lo extranjero y lo local, donde es precisamente el campo semántico de lo negativo el que define a ese otro de allá, contrario al yo, que se describe a partir de un campo semántico de lo positivo. Nuevamente, la maldad se reconoce en la otredad, como lo extranjero.

Es notable la preocupación constante por la definición del ser a partir de la otredad tanto en las letras de Black Sabbath como en la obra teatral A puerta cerrada, lo cual refuerza la correlación del yo y el nosotros, pero a la vez genera una repulsión recíproca provocada por la constante y eterna mirada inquisitiva de la pluralidad hacia la singularidad: "Acordaos de que yo estoy aquí y que os estoy mirando. No dejaré de miraros ni un solo momento..." (Sartre, 1944, p.28).

En esta obra teatral sartreana, Estelle, una de las protagonistas de la historia, entabla una conversación con Inés, personaje con quien Estelle se encuentra atrapada en el Infierno. En este diálogo, Estelle asegura que cuando no se ve, cuando su reflejo está ausente (en el infierno de esta 
obra no existe ningún espejo) su existencia se vuelve dudosa, "Cuando no me veo, tengo que palparme... Me pregunto si existo verdaderamente" (1944, p.16).

A falta de un espejo donde reconocerse, la única solución que tiene para validar su existencia es ver su reflejo en los ojos de Inés. Se trata de una relación de identificación entre el castigado -Estelle- y el castigador -Inés-, a quien se le otorga el poder de hacer que una persona exista a través de las proyecciones en sus ojos. No les es posible vivir juntas porque les resulta un infierno comprender que pasarán toda su existencia juntas, pero tampoco pueden vivir alejadas, pues es en la mirada de la otra persona donde se tornan en seres reales, existentes. Como en un juego de espejos, en el momento en que observa su reflejo en la mirada del otro, entonces se convence de que existe y puede conocerse, pero sólo como lo ven los ojos del otro.

Tanto en A puerta cerrada, como en Solitude, de Black Sabbath, los personajes logran abrir la puerta infranqueable del infierno para escapar de él. Sin embargo, la abrumadora libertad hace titubear a los prisioneros:

Inés. - ¿Y tú? (A Estelle) Entonces, ¿quién? ¿Cuál de los tres? La vía está libre. ¿Quién nos retiene? ¡Ah, es para morirse de risa! Resulta que somos inseparables (Sartre, 1944, p.32).

El mundo es un lugar solitario, estás sólo/ [...] tú sólo reíste cuando te pedí que te quedaras / no he parado de llorar desde que te fuiste... ${ }^{3}$ (Black Sabbath, 1971c).

La posibilidad de liberarse del verdugo es tangible, tan real como el temor a la libertad misma, al vacío, a la incertidumbre, al desierto, a lo desconocido, a la otredad, pero, sobre todo, a la no- trascendencia, lo cual los hace desistir de salir y separarse de él. Al abrir la puerta, ninguno de los personajes intenta traspasarla y liberarse. En ese fragmento de Solitude, a pesar de que el verdugo ha abandonado al enunciante, este continúa llorando su ausencia y sintiendo la soledad del mundo. Ellos existen en su alter ego y sin ellos expresaría Nietzsche- "el desierto crece".

\footnotetext{
3 "The world is a lonely place - you're on your own/ [...] You just laughed when I begged you to stay / I've not stopped crying since you went away..."
} 
Las víctimas se mantienen al lado de su verdugo y espejo, ya que en ellos su existencia es tangible, visible. En la alteridad se muestran y se apropian de sí mismos, hasta lograr el desdoblamiento de la identidad en un proceso de fusión ${ }^{4}$ de seres. No hay tortura física ni sufrimiento corporal, sin embargo, todos ellos se encuentran en el infierno; son condenados eternamente al desdoblamiento, a estar unidos y a la vez escindidos de su otredad, siendo uno la némesis del otro: "no hay necesidad de parrillas, el infierno son los otros" (Sartre, 1944).

¿Qué pasa entonces con el infierno donde los cuerpos se calcinan y las almas arden? Ahora se materializa en la Guerra, en el infierno terrenal que describe Black Sabbath en su canción Hand of doom: "Primero fue la bomba, el napalm de Vietnam/ [...] escapas de la vida, la realidad es así". (Black Sabbath, 1970a). ${ }^{5}$

"¿Y dios le permitió esa Guerra? ...Este dice que nada sucede sin su permiso", pregunta La mujer en El diablo y dios, a lo cual el panadero responde: "Nada, a excepción del mal que nace de la perversión de los hombres" (Sartre, 1986, p.21). Black Sabbath responde también esa pregunta con los versos de Lord of this world: "Tu mundo fue hecho para ti por alguien de arriba/ pero tu elegiste formas malvadas en lugar del amor". (Black Sabbath, 1971b). ${ }^{6}$

No es que dios haya convertido el mundo en un infierno, fue el hombre mismo en su libre albedrío quien eligió su infierno, aunque al hacerlo, condena también a sus semejantes a vivirlo. "Yo quiero elegir mi propio infierno", afirma Inés (Sartre, 1944, p.18), por eso teme tanto su libertad, pues se hace consciente de que ella es libre de crear un nuevo infierno para los otros. El castigo para esta libertad que condena a los demás al abismo es el infierno del sufrimiento en la tierra, la desesperanza y la incertidumbre.

\footnotetext{
${ }^{4}$ Elena Otto Cantón, en su artículo "El tema del doble en William Wilson, de E.A. Poe", explica que hay tres procedimientos a partir de los cuales se puede llegar al desdoblamiento de la identidad: la metamorfosis de un sujeto bajo diferentes formas, la fusión de dos individuos originalmente distintos en uno solo y la fisión de un solo individuo en dos personalidades. $(2005$, p.1)

5 "First it was the bomb, Vietnam napalm, disilusioning, you push the needle in/ from life you escape, reality's that way" 6 "Your world was made for you by someone above / but you chose evil ways instead of love"
} 
El verdugo de los verdugos es Satán, quien asciende para hacer de la Tierra su reinado, propagando entre los espíritus el odio hacia sus semejantes traducido en maldad hacia el mundo, misma que finalmente enferma esas almas de un padecimiento para el cual no existe cura ni expiación, explica Black Sabbath, “... puercos de guerra arrastrándose / pidiendo misericordia por sus pecados / Satán, riendo, extiende sus alas [...]". (Black Sabbath, 1970b). ${ }^{7}$

Sartre, en cambio, abre la puerta a una oportunidad de redención. Sin embargo, son los prisioneros mismos quienes rechazan la salvación al renunciar al exilio y abrazan el destino de la fatalidad infernal a cambio de asir la certidumbre de la existencia que les proporciona la otredad,

INÉS. - ¡Muerta! iMuerta! iMuerta! Ni el cuchillo, ni el veneno, ni la cuerda. Ya está hecho, ¿comprendes? Y estamos juntos para siempre. (Ríe.)

ESTELLE (lanzando una carcajada). - ¡Para siempre, Dios mío, iqué raro! ¡Para siempre! GARCIN (ríe mirando a las dos). - ¡Para siempre! (Sartre, 1944, p.56).

En síntesis, aunque el infierno se transporta a la Tierra en el presente y al plano espiritual después de la muerte, los símbolos del infierno no se alteran sustancialmente con respecto a la concepción tradicional cristiana del infierno. El fuego expiatorio, Satán como el señor de las tinieblas, la localización del infierno en un plano inferior y subterráneo, el descenso de los condenados al infierno, el Juicio Final, la condena, se mantienen como símbolos representativos de este espacio de castigo, principalmente en la obra de Black Sabbath. Sin embargo, estos referentes se deconstruyen en la estructuración de los espacios sacros y profanos en la obra de Sartre, se resignifican y adaptan a un infierno más tangible y se actualizan a las problemáticas y requerimientos sociales de una explicación racional sobre el bien y el mal, más allá de lo meramente mítico o metafísico.

La constante entre la expresión del bien y el mal en Black Sabbath y Sartre consiste pues en que ambos conservan los signos y símbolos cristianos de la maldad, pero resemantizados de tal manera que se transforman en una metáfora del desencanto y el nihilismo de una Europa del siglo

7 “...war pigs crawling/ begging mercy for their sins / Satan, laughing, spread hi swings". 
XX, de la modernidad, en la que el imaginario colectivo está constituido más por símbolos de la realidad concreta que por íconos míticos intangibles.

En los textos de Sartre podemos advertir una separación de la cosmovisión canónica del mito del infierno. Deconstruye el mito católico para erigir un infierno a la medida de una sociedad sumida en un contexto bélico en torno a temas como la alienación, el capitalismo, la destrucción, la guerra y la desvalorización del plano espiritual.

El extranjero, de Camus, el ello freudiano, lo Umheimlich del hombre kafkiano, el Superhombre nietzscheano, así como La pantera de Rainer Maria Rilke, no son más que representaciones arquetípicas que aluden al infierno existencialista, cuyo eco resuena en las canciones de Black Sabbath: el infierno de tener que soportarse a sí mismo eternamente como un sujeto escindido, cuya condena consiste en buscar en el otro su "otra mitad" platónica que, no obstante, se convierte en su juez y verdugo, en su infierno y, aun así -como en síndrome de Estocolmo- se mantiene unido a él:

Somos víctimas -pensaba yo- de un doble espejismo. Si miramos afuera y procuramos penetrar en las cosas, nuestro mundo externo pierde en solidez, y acaba por disipársenos cuando llegamos a creer que no existe por si, sino por nosotros. Pero, si convencidos de la íntima realidad, miramos adentro, entonces todo nos parece venir de fuera, y es nuestro mundo interior, nosotros mismos, lo que se desvanece. ¿Qué hacer entonces? (Machado, 2006, p.274).

\section{Referencias}

Ballesteros, A. (1998) Narciso y el doble en la literatura fantástica victoriana. Cuenca: Universidad de Castilla -La Mancha.

Black Sabbath (1969) Wicked world. En Black Sabbath [CD]. Londres: Vertigo Records.

Black Sabbath (1970a) Hand of doom. En Paranoid [CD]. Londres: Vertigo Records.

Black Sabbath (1970b) Luke's Wall / War pigs. En Paranoid [CD]. Londres: Vertigo Records.

Black Sabbath (1971a) Into the void. En Master of reality [CD]. Londres: Vertigo Records. 
Black Sabbath (1971b) Lord of this world. En Master of reality [CD]. Londres: Vertigo Records.

Black Sabbath (1971c) Solitude. En Master of reality [CD]. Londres: Vertigo Records.

Machado, A. (2006). Campos de batalla. España: Cátedra

Minois, G. (2005) Historia de los infiernos. Barcelona: Paidós.

Otto, E. (2005) El tema del doble en William Wilson de E.A. Poe. En Espectáculo. Revista de estudios literarios. Obtenido de Universidad Complutense de Madrid. http://www.ucm.es/info/especulo/numero30/wwison.html.

Ruiz, J. (2007) “Introducción”. En Alteridad un recorrido filosófico. Tlaquepaque: ITESO. Sartre, J. (1944) A puerta cerrada [Huis clos]. Alfonso sastre, traductor. [PDF]

Sartre, J. (1986) El diablo y dios. Madrid: Alianza Losada. 